\section{Structure of Native and Mercerized Celluloses}

THe crystal unit-cells proposed by $\mathrm{K}$. Meyer and H. Mark ${ }^{1}$ and K. Meyer and L. Mish ${ }^{2}$ for cellulose lattices I and II, and for which there seemed to be general agreement, have been discussed recently by M. K. Sen and S. C. Roy ${ }^{8}$. These authors have given a new interpretation to $\mathrm{X}$-ray diagrams obtained from these fibres, based on the existence of a strong diffraction intensity corresponding to a reticular distance of the order of $14 \mathrm{~A}$. This interference result had hitherto not been observed for these substances. This new interpretation has been considered with certain reservations by $\mathrm{G}$. $\mathrm{O}$. Warwicker and H. J. Vellard 4 , who have pointed out the causes of errors already remarked upon by other investigators. H. J. Woods ${ }^{5}$, on the other hand, has observed a small-angle spot for jute very near that observed by Sen and Roy.

It seemed worth while to us to repeat this work on a group of textile fibres (ramie, viscose, linen, 'Fortisan', etc.) using experimental techniques beyond criticism.

X-ray diagrams were obtained with a diffraction camera which was designed especially for fibre studies ${ }^{6}$. In brief, the film is placed in a vacuum, the $X$-ray beam coming from a copper anticathode is monochromatized by reflexion from a curved quartz crystal, and the focalization is exact for all angles within the equatorial plane (Guinier $^{7}$ ).

The diffraction diagrams may be obtained up to approximately $20 \mathrm{~A}$. Furthermore, the mounting of a double monochromator ${ }^{8}$ in a vacuum, making it possible to obtain diagrams at very small angles, permits us to record the diffusion from $200 \mathrm{~A}$. up to reticular distances corresponding to intense equatorial interferences of the cellulose fibres (101) and $(10 \overline{\mathrm{I}})$, or $(101)$ for mercerized cellulose. Diagrams were obtained
(I)

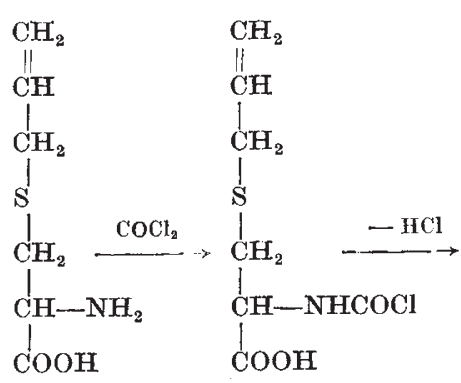

beam from a tube having a chromium anode, we have observed the spots noted by Sen and Roy. Moreover, monochromatization of the beam caused these spots to disappear. This proves that in the case of substances which are as badly crystallized as the textile samples, one must give special attention to experimental techniques, and in particular to the composition of the X-ray beam used.
C. Legrand
A. Guinier
A. Bonnemayre
P. AnTzenberger

Institut Textile de France.

Conservatoire des Arts et Métiers.

1 Meyer, K, and Mark, H., Z, phys. Chem., B, 115 (1929).

2 Meyer, K., and Mish, L., Helv. Chim. Acta, 20, 234 (1937).

${ }^{3}$ Sen, M. K., and Roy, S. C., Nature, 173, 298 (1954).

4 Warwicker, G. O., Nature, 174, 135 (1954). Vellard, H. J., Nature, $174,135(1954)$.

s Woods, H. J., Nature, 174, 136 (1954).

- Legrand, C., J. Polymer Sci., 8, 3, 337 (1952).

7 Guinier, A., Ann. de Phys., 12, 161 (1939).

8 Fournet, G., and Guinier, A., C.R. Acad. Sci., Paris, 226, 656 (1948).

\section{Synthesis of Poly-S-Allylcysteine (Poly-Deoxo-Alliin)}

$\mathrm{W}_{\mathrm{E}}$ wish to report briefly on the synthesis of polyS-allylcysteine (IV) (poly-deoxo-alliin), from 1-Sallyleysteine (I), by the route indicated in the scheme:

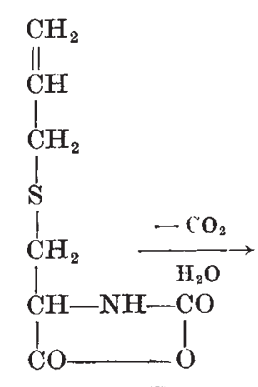

(III)

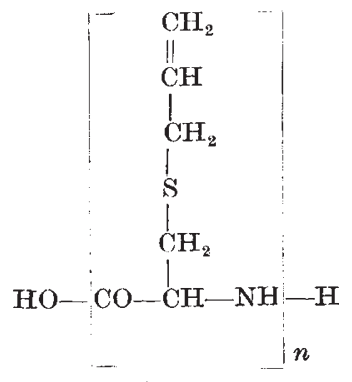

(IV)<smiles>C=CCNC(=O)C(CSCC=C)NCCCSCC(NC(=O)OCC)C(=O)OCC</smiles>

1-S-Allylcysteine, prepared according to Stoll and Seebeck ${ }^{1}$, yielded the appropriate $\mathrm{N}$-carboxyanhydride (III), via the intermediary chloride (II), on passing phosgene for about two hours at $60^{\circ}$ through a suspension in dry dioxane. The solution was evaporated in vacuo at $40^{\circ}$ and the residue kept overnight in a vacuum desiccator over phosphorus pentoxide. The remaining crystalline mass (melting point about $50^{\circ}$ ) was recrystallized from dry ethylacetate - petroleum ether, and the pure N-carboxyanhydride (III) melted. at $55^{\circ}$ with resolidification at about $115^{\circ}$.

Polymerization of (III) was carried out either in solution or in bulk in high vacuum. Pyridine, dioxane (with the addition of a trace of water when working in the cold or dry if heating to about $100^{\circ}$ ), glacial acetic acid or ethanol was used as solvent. On heating in bulk in a high vacuum, actual polymerization took place only on raising the temperature considerably above the melting point of (III) - at about $150^{\circ}$; at temperatures of about $100-105^{\circ}$, 